\title{
Dental Assistance to the Child and Adolescent with Autistic
}

\section{Spectrum Disorder}

\begin{abstract}
Pinho RCM*
Federal University of Pernambuco, Brazil

*Corresponding author: Roberto Carlos Mourao Pinho, Federal University of
\end{abstract}

Pernambuco, Brazil, Email: robertomouraopinho@yahoo.com.br

\section{Editorial}

Volume 1 Issue 1

Received Date: November 17, 2018

Published Date: November 23, 2018

DOI: $10.23880 /$ jqhe- 16000104

\section{Editorial}

The term autism has an atypical history. Named in 1906 by Plouller when studying the thought processes of patients with a diagnosis of dementia, the term was only disseminated in 1911 by a report from Swiss psychiatrist Eugen Bleuler, who indicated it to be one of the fundamental symptoms of schizophrenia [1]. Eugene Bleulerinitially described autism in 1911as a disturbance characterized by an alteration in the relationships that normally exist between the inner world and outer environment [2,3]. Over-emphasis on the former constitutes autism. In autism with some intensity, the affected individual maintains insufficient contact with the environment, avoids social relations and lives in a fantasy world in which desires are taken to be satisfied and fears and persecutions are taken to be true. In autism, reality loses its affective and logical meaning to a greater or lesser extent. Affected individuals move about in the outer world governed by their desires and deliriums that which is contrary to their complexes has no affective or intellectual meaning [2-4]. However, the first descriptions related to autism were given by Kannerin 1943 [5-10] and were based on observations of the behavior of 11 children whose most striking shared characteristic was an apparent detachment from society. They also exhibited motor stereotypes, such as walking on the tips of the toes, rocking the body and idiosyncrasies regarding the use of language, such as pronominal inversions and a monotone vocal rhythm [11]. Kanner denominated this condition "early childhood autism" [12].

Autism is a behavioral syndrome with multiple etiologies that compromises child development [13]. The prevalence in the world population is approximately $1 \%$. Autism affects males more than females and co morbidities are common, as more than $70 \%$ of affected individuals have concomitant conditions [14]. These individuals also have persistent deficits in imaginative capacity [15], social communication and social interactions in multiple contexts. In the category of pervasive development disorders, the autistic spectrum includes autistic disorder, Asperger's disease, unspecified developmental disorders, childhood disintegrative disorder (Heller's syndrome) and Rett syndrome. This group of disorders is characterized by a shared spectrum of qualitative impairment regarding social interactions associated with different degrees of communication deficits, repetitive behaviors and restricted interests. Pervasive development disorders are currently commonly called the autism spectrum disorder [16].

Health care for individuals with autism spectrum disorder is complex, with the involvement of many needs on the part of both the individual and his/her family. Medical care is generally considered a priority, whereas oral health care is often not performed in a timely manner and is most often limited to emergency treatment, which is hindered by the cognitive and behavioral impairments of the patient. Therefore, an understanding of the behavioral approach to dental care for children and adolescents with autism spectrum disorder is of fundamental importance, since dental treatment is an initiator of anxiety and fear. This anxiety can be further increased in patients with special needs and their parents/caregivers when dentists lack knowledge on the behavioral techniques. Due to the difficulty in managing and conducting care for children and adolescents with autism spectrum disorder, the first dental appointment often only occurs in adulthood, without the patient ever having seen a dentist before, which hinders the success of treatment. 


\section{Journal of Quality in Health Care \& Economics}

Dental care for children and adolescents with autism spectrum disorder is a challenge whether due to their limited previous experience with a dentist or due to their intellectual impairment. Dental care for this population should employ a psychological approach based on the behavior of the individual and the conditioning for the practice during dental interventions in the clinical setting. For such, behavior analysis can be successfully applied to autism with satisfactory results.

\section{References}

1. Dias S (2015) Asperger e sua síndrome em 1944 e na atualidade. Rev LatinoamPsicopat Fund 18(2): 307313.

2. Bleuler E (2014) Dementia praecox oder Gruppe der Schizophrenien. Bernhard Küchenhoff, pp: 1-15.

3. Bleuler E (2018) Affectivity, suggestionability and paranoia 21(89): 72-77.

4. Campos MO (2010) The group of schizophrenias or dementia precoce. Report presented to the III Brazilian Congress of Neurology, Psychiatry and Legal Medicine. Rio de Janeiro. July 1929. History, Science, Health-manguinhos 17(S2): 709-732.

5. Kanner L (1968) Autistic disturbances of affective contact. Acta Paedopsychiatr 35(4): 100-136.

6. Kanner L (1943) Autistic disturbances of affective contact. Embryo Project Encyclopedia 2: 217-250.

7. Kanner L (1973) The birth of early infantile autism. J Autism Child Schizophr 3(2): 93-95.
8. Kanner L (1973) Historical perspective on developmental deviations. J Autism Child Schizophr 3(3): 187-198.

9. Kanner L (1994) Irrelevant and metaphorical language in early infantile autism. 1946. Am J Psychiatry 151(6): 161-164.

10. Kanner L (1955) Follow-up study of eleven autistic children originally reported in 1943. 1971. Psychiatr Enfant 38(2): 421-461.

11. Klin A (2006) Autism and Asperger's Syndrome: An Overview. Brazil Journal of Psychiatry 28(S1): S3-S11.

12. Mesquita WS, Pegoraro RF (2013) Diagnóstico e tratamento do transtorno autístico em publicações brasileiras: revisão de literatura Diagnosis and treatment of autistic disorder in brazilian publications. J Health Sci Inst 31(3): 324-329.

13. Andrade AA, Martins Teodoro ML (2012) Família e Autismo: Uma Revisão da Literatura. Family and Autism: A Literature Review 5(2): 133-142.

14. Lai MC, Lombardo MV, Baron Cohen S (2014) Autism. Lancet 383(9920): 896-910.

15. Davis PE, Simon H, Meins E, Robins DL (2018) Imaginary Companions in Children with Autism Spectrum Disorder. Journal of Autism and Developmental Disorders 48(8): 2790-2799

16. American Psychiatric Association (2001) DSM-5 American Psychiatric Association Porto Alegre. Artmed, pp: 976. 